\title{
MOTIVAÇÃO DE ESTUDANTES NON-MAJORS EM UMA DISCIPLINA DE PROGRAMAÇÃO
}

\author{
$\underline{\text { José Solenir Lima Figuerêdo }} \mathbf{1}^{\mathbf{1}}$ e Roberto Almeida Bittencourt ${ }^{2}$ \\ 1. Bolsista PIBIC/CNPq, Graduando em Engenharia da Computação, Universidade Estadual de Feira de Santana, e- \\ mail: solenir.figueredo@gmail.com \\ 2. Orientador, Departamento de Exatas, Universidade Estadual de Feira de Santana, e-mail: roberto@uefs.br
}

PALAVRAS-CHAVE: Aprendizagem; Programação; Motivação.

\section{INTRODUÇÃO}

Programar computadores é considerada uma competência complexa de se aprender por envolver uma variedade de conhecimentos, estratégias e modelos nos diferentes níveis de domínio do problema, do design de solução e do programa propriamente dito Robins et al. (2003). Neste contexto, disciplinas de introdução à programação geralmente apresentam altos índices de abandono e reprovação Watson \& Li (2014). Apesar de muitas iniciativas visando a resolução deste problema, estudos evidenciam que as taxas não têm melhorado significativamente ao longo do tempo Watson \& Li (2014).

Disciplinas de introdução a programação, rotineiramente chamadas de CS1 (Computer Science 1) na literatura, costumam fazer parte das matrizes curriculares de cursos de graduação fora da área de TI, principalmente nas ciências exatas e tecnológicas. Adotamos aqui o termo inglês non-majors para identificar os estudantes que cursam uma disciplina (neste caso, CS1) de uma área diferente da que se graduam. Entendemos que as disciplinas de introdução a programação ofertadas podem ser adaptadas para melhor atender este público. Várias iniciativas buscam potencializar a motivação e comprometimento dos estudantes Forte \& Guzdial (2005), como cursos focados na habilidade de resolução de problemas, contextualizados para a área do estudante, utilizando as linguagens Logo e Python, utilizando ferramentas como Scratch e Greenfoot, ou utilizando mídias e a ferramenta Jython Environment for Students (JES).

A motivação já vem sendo apontada como um fator importante na aprendizagem há algum tempo. Compreendendo a sua importância, percebe-se que a abordagem empregada pode contribuir para o aumento ou diminuição da motivação dos estudantes Jenkins (2001). Para melhor atuar sobre as diversas dimensões da motivação, Keller (1987), criou o modelo ARCS (Atenção, Relevância, Confiança e Satisfação), que inclui um conjunto de estratégias utilizadas para aumentar o apelo motivacional de materiais instrucionais. A partir do modelo ARCS, Keller desenvolveu um instrumento de medição chamado de Instructional Material Motivation Survey (IMMS) para identificar possíveis problemas motivacionais em materiais instrucionais. Este instrumento consta de 36 declarações sobre o material, gerados a partir das categorias definidas pelo ARCS.

O trabalho desenvolvido investiga como uma abordagem de ensinoaprendizagem de programação para calouros de engenharia Civil, que faz uso do ambiente Scratch, da linguagem de programação Python e do ambiente de desenvolvimento JES, influencia na motivação dos estudantes. A avaliação é realizada a 
partir de um questionário adaptado do IMMS ao contexto da abordagem, além de uma avaliação qualitativa.

\section{METODOLOGIA}

O presente trabalho foi orientado a partir dos métodos mistos de pesquisa, utilizando uma estratégia concomitante. Os métodos mistos combinam os métodos predeterminados das pesquisas quantitativas com métodos emergentes das qualitativas Creswell (2010). O estudo foi realizado com uma turma da disciplina de Introdução a Ciência da computação (ICC) do curso de Engenharia Civil de nossa universidade, ao longo do semestre letivo 2016.1. Escolhemos este curso por oferecer a disciplina no primeiro semestre para os calouros.

A turma teve 40 alunos, todos estudantes calouros de Engenharia Civil. Antes de iniciar a pesquisa elaboramos um termo de consentimento livre e esclarecido (TCLE), descrevendo justificativas, objetivos e possíveis riscos e benefícios ao participar do estudo, além de garantir o anonimato dos participantes. Após lerem o TCLE, restaram 36 participantes, sendo 27 do sexo masculino e 9 do feminino.

A disciplina de ICC tem carga horaria de 60 horas, divididas entre 30 horas práticas e 30 teóricas. Duas turmas práticas de 20 alunos são apoiadas pelo professor e por um monitor. A disciplina foi dividida em três unidades, cada uma com uma ferramenta diferente. A utilização de jogos e mídias procurou oferecer um contexto mais adequado e significativo, dado o perfil dos estudantes: entre 17 e 19 anos, uso de redes sociais por meio de dispositivos moveis e afinidade por jogos.

Como instrumentos qualitativos, realizamos observações das aulas teóricas e das práticas laboratoriais, bem como entrevistas semiestruturadas com alguns participantes. Ao longo da pesquisa foram realizadas duas entrevistas, sendo que o guia da segunda entrevista observou as quatro dimensões definidas pelo modelo ARCS. Em relação aos instrumentos quantitativos, fizemos uso de três questionários. Dois destes possibilitaram inferir percepções sobre motivação, tendo sido elaborados a partir dos construtos do IMMS.

$\mathrm{Na}$ análise dos questionários, tabulamos dados e geramos estatísticas descritivas e inferenciais, evidenciando características importantes sobre motivação. Em contrapartida, com os dados qualitativos das observações e entrevistas, fizemos uma análise descritiva, por meio do processo de codificação, gerando memorandos e descrição de categorias, as quais foram utilizadas para conceber uma classificação de condições que despertam, mantem ou diminuem a motivação. Por limitação de espaço, não apresentaremos os resultados detalhados, apenas a discussão destes.

\section{DISCUSSÃO}

Percebemos, a partir da abordagem de ensino utilizada, um conjunto de variáveis que podem influenciar positivamente ou negativamente na motivação dos estudantes. Como possíveis variáveis que despertam ou mantêm a motivação, no contexto de ensino de programação, destacamos o feedback neutro e de processo, a utilização de jogos, a existência de scaffolding, a importância das aulas práticas, a promoção da autonomia, exercícios utilizando uma escala gradual de dificuldade e êxito na conclusão dos exercícios. No que concerne às variáveis que diminuem a motivação, evidenciamos a 
não conclusão de uma atividade, a didática do professor, exercícios de programação feitos no caderno, idioma estrangeiro e mudança brusca da dificuldade de um assunto.

O Scratch e o Python com mídias apresentaram diferentes impactos na motivação. De maneira geral, a primeira unidade obteve avaliações mais positivas que as seguintes.

A escolha do Scratch para a primeira unidade objetivou promover uma introdução mais branda aos conceitos iniciais de programação e potencializar a motivação dos estudantes. Conforme identificado nos dados, a ferramenta exerceu de fato este papel. O Scratch possui um design agradável e o modo como o conteúdo está disposto e foi abordado contribuiu para o aumento da atenção dos estudantes. Além disso, a utilização do Scratch num contexto de criação de jogos estimula a criatividade, o que também ajudou a manter a atenção dos estudantes.

Por outro lado, o Scratch não passou a sensação de utilidade prática na vida dos estudantes, o que diminui sua relevância percebida (como na típica pergunta: "Porque eu tenho que estudar isso?". Mas, segundo Keller (1987), a sensação de relevância pode vir do modo de ensinar, satisfazendo certas necessidades pessoais, como dar a pessoas com "necessidade de realização" a oportunidade de estabelecer metas e assumir a responsabilidade de alcançá-las. Neste sentido, percebemos que o Scratch foi positivo.

A satisfação está relacionada com as demais categorias, principalmente com a relevância percebida. As práticas de ensino devem contribuir para que os estudantes se sintam bem com suas realizações. Percebamos que uma dessas realizações é o fato de finalizar as atividades com êxito, trazendo grande satisfação para quem alcança essa meta.

A utilização de Python no contexto de mídias, apoiado pela ferramenta JES, também foi pensada para oferecer um contexto mais motivador, mais próximo da realidade dos jovens. No entanto, os resultados dos construtos de atenção e confiança levam a crer que, embora as primeiras aulas tenham sido interessantes e mantido a atenção dos estudantes, os conceitos não foram de fácil compreensão. Além disso, a maioria dos estudantes avaliaram negativamente a organização do conteúdo e a quantidade de conceitos abordados, o que leva a crer que houve uma transição brusca na complexidade do conteúdo, contribuindo para diminuir a motivação.

A relevância percebida em termos de utilidade prática foi baixa, o que, de certa forma, era esperado, já que a escolha da ferramenta e definição da abordagem consideraram a relevância em termos de "necessidade pessoal". Mas isto também não foi percebido pelos estudantes, já que a maioria deles não conseguiu relacionar o material visto com sua vida ou com conhecimentos prévios.

A maioria dos estudantes não concordaram que o JES é uma ferramenta que auxilia os novatos em programação. No entanto, consideraram importante finalizar as atividades e, em sua maioria, se sentiram bem ao completar as atividades com êxito, o que gerou percepções contraditórias sobre satisfação.

Alguns fatores externos podem ter influenciado os resultados para a terceira unidade. Uma das possíveis causas foi o desgaste sofrido devido a uma greve estudantil na unidade que o JES foi utilizado, provocando uma sensação de descontinuidade. Um outro aspecto que pode ter influenciado foi o idioma da ferramenta. Finalmente, houve mudança de professor da turma teórica na terceira unidade, o que pode também ter 
comprometido o processo pedagógico. Mas apesar da avaliação negativa, nenhum estudante abandonou a disciplina na terceira unidade.

\section{CONCLUSÃO}

Este resumo apresenta um estudo que analisa a motivação de estudantes nonmajors calouros que cursaram uma disciplina de Introdução a Ciência da Computação, utilizando uma abordagem adaptada para este fim, com o ambiente Scratch e com a linguagem Python combinada com desenho de figuras e manipulação de imagens.

Percebemos que o ambiente Scratch pode proporcionar o aumento da motivação dos estudantes, contribuindo para seu aprendizado, realçando seu potencial para ensinar os conceitos iniciais de programação. Todavia, com a ferramenta JES no contexto de imagens, os resultados preliminares são diferentes, sugerindo que o JES não conseguiu motivar os estudantes satisfatoriamente. Este resultado pode ser devido ao ambiente, ou pode ser fruto de um conjunto de complicações ocorridos na terceira unidade da disciplina, o que demanda uma investigação adicional posterior.

Evidenciamos, também, a existência de um conjunto de variáveis que podem influenciar diretamente na motivação, contribuindo para despertá-la, mantê-la ou diminui-la, conforme apresentado em detalhes na discussão. Estes resultados são relevantes, pois fornecem indicativos de estratégias que professores podem utilizar na promoção da motivação, ou mesmo para evitar a sua diminuição.

\section{REFERÊNCIAS}

CRESWELL, J. W. (2010). Projeto de pesquisa métodos qualitativo, quantitativo e misto. In Projeto de pesquisa métodos qualitativo, quantitativo e misto. Artmed.

FORTE, A; GUZDIAL, M. (2005). Motivation and nonmajors in computer science: identifying discrete audiences for introductory courses. IEEE Transactions on Education, 48(2):248-253.

JENKINS, T. (2001). Teaching programming-a journey from teacher to motivator. In The 2nd Annual Conference of the LSTN Center for Information and Computer Science.

KELLER, J. M. (1987). Development and use of the ARCS model of instructional design. Journal of instructional development, 10(3):2-10.

ROBINS, A.; ROUNTREE, J.; ROUNTREE, N. (2003). Learning and teaching programming: A review and discussion. Computer Science Education, 13(2):137-172.

WATSON, C; LI, F. W. B. (2014). Failure Rates in Introductory Programming Revisited. In Proceedings of the ITiCSE 2014, pages 39-44, New York, NY, USA. ACM. 